\title{
Pharmaphobes, pharmascolds and conflict denialists
}

\section{Part III of a series on conflicts of interest in medicine (Part I, Part II)}

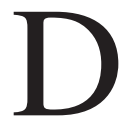

r. Lisa Rosenbaum expected some backlash. She knew the subject she was writing about was controversial. Heck, the topic itself contains the word "conflict." And yet, despite this, she was still surprised by the flood of angry responses to her articles.

"I've written things before and people haven't liked it, and I'll get a few emails telling me how I was wrong," said Rosenbaum, a cardiologist and national correspondent for the New England Journal of Medicine. "I've angered people before but certainly not to this extent."

The much-criticized articles in question are a three-part series that explore the trade-offs of regulating conflicts of interest in relationships between physicians and the pharmaceutical industry. According to Rosenbaum, one of her goals in writing the articles, published earlier this year in the New England Journal of Medicine, was to closely examine what she calls "an interesting collision of emotion and reason." There is often a knee-jerk reaction to conflicts of interest in medical research, she said, and a tendency to focus only on the risks of physician-industry relationships while ignoring potential benefits.

"Before we can have a reasoned debate, we need to get past the emotion," said Rosenbaum. "Nobody wins when pharma sponsors a trial with robust data and we refuse to use it."

The numerous and often ireful responses to the articles, however, illustrate just how difficult it is to have a dispassionate conversation about conflicts of interest. Many readers appear to view her essays as little more than pro-industry cheerleading. Let's just say critics weren't exactly scarce.

Some written responses had rather benign titles, such as "Why Lisa Rosenbaum Gets Conflict of Interest Policies Wrong" and "Say It Ain't So:

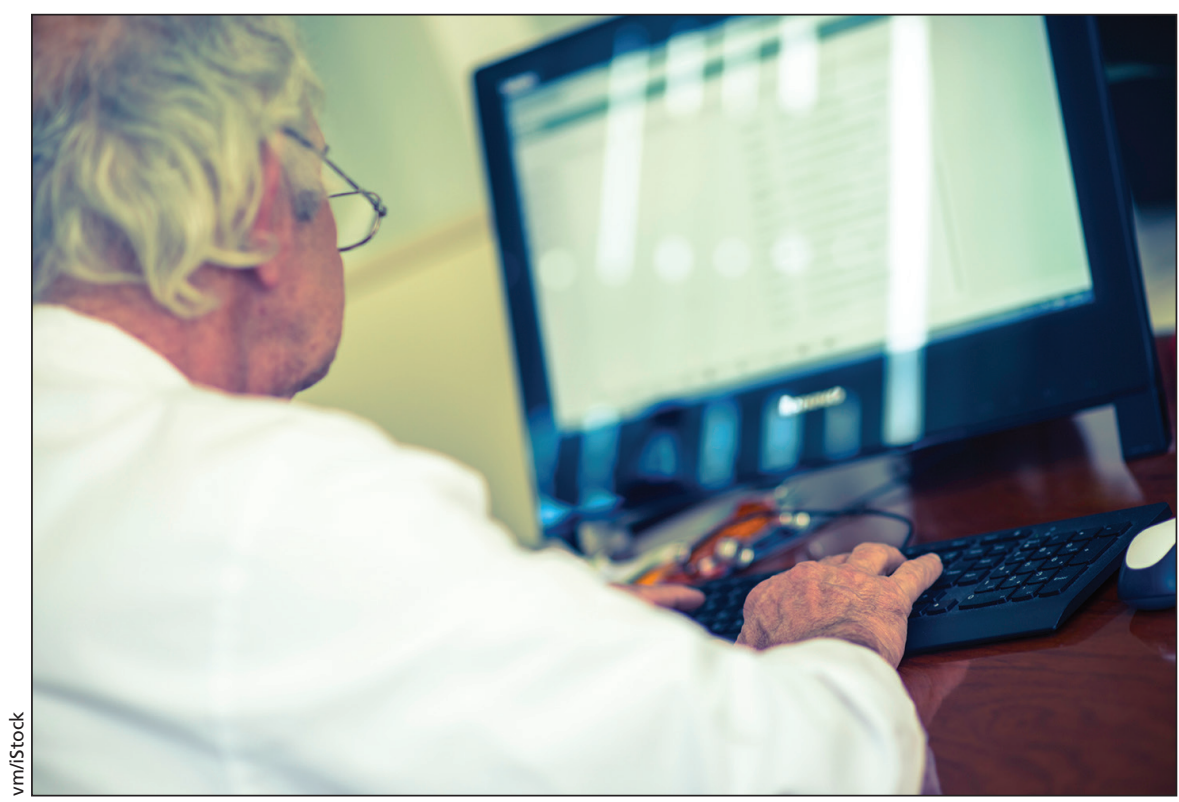

If you write a defence of physician-industry relationships, expect some angry emails.

Logical Fallacies in Defense of Conflicts of Interest ... in the New England Journal of Medicine?" Others were more blunt, including "The Conflict Denialists Strike Back" and "New England Journal of Medicine Auditions For the Role of the Fox News of Healthcare." One critic dismissed Rosenbaum's arguments as a struggle to "persuade us that all this talk of bias harming patients is a naughty lie," which is "quite sweet but I'm not sure what it is doing in a leading medical journal."

Well, according to the editor-inchief of that medical journal, Dr. Jeffrey Drazen, there is a simple reason the articles appeared in his pages. "I wanted a conversation to start, because right now you can't even mention this," said Drazen. "It's like how at a synagogue supper you can't talk about ham sandwiches."

Finding a way to work with drug companies, which have far greater financial resources than academic laboratories, can lead to the development of new medicines for patients, said Drazen. Sure, managing conflicts of interest is important, he noted, but this is a com- plex problem and people should consider the subtleties on a case-by-case basis rather than jump to conclusions.

"There are a group of people, and I think a predictable group of people, who feel that any interaction [with industry] is bad, and there are others who feel that we should think about this," said Drazen. "The way you understand something more is by talking about it. And we hope people will talk about this in a civilized way, and that we won't be calling each other names and saying things like "you sold out to the dark side of the force."

Of course, some people who defend physician-industry relationships also aren't shy about coining monikers for people who oppose their views. One of the most vocal critics of the antipharma crowd is Dr. Thomas Stossel, director of translational medicine at Brigham and Women's Hospital in Boston, Massachusetts. In fact, he wrote a book, Pharmaphobia, to rebut what he says is a growing sentiment in some corners that pharma can do no right.

"There are inveterate pharmaphobes, I call them, who know all the 
answers before the questions are asked," said Stossel (who also uses the term "pharmascolds"). "This is not a difference of opinion. This is flat earth versus round earth. That makes it hard to debate these people."

It does seem that many people are "talking past each other" on this topic, said Dr. Vikas Saini, president of the Lown Institute, a nonprofit health care think tank in Massachusetts. In most conversations about conflicts of interest, people also paint with too broad a brush, said Saini. There are many steps in the process of innovation in medicine, each requiring a different understanding about conflicts of interest and a different set of rules to govern them. As for Rosenbaum's series of articles on the topic, Saini views them as mostly straw man arguments.

"The answer is not to just attack the critics [of physician-industry relationships]," he said. "The answer is to solve the problem."

The pharmaceutical industry will always need access to patients to test new products. And because physicians are the people who control that access, the need for drug companies to have relationships with doctors is somewhat incontrovertible, said Saini. So the question is not: should collaboration be allowed? But rather: at what stage of the drug development process and under what conditions?

It is one thing, for instance, for industry and physicians to collaborate at the idea stage, or even on a pilot study. It is quite another, however, to receive input on the design of a pivotal clinical trial from a company that stands to make tens or even hundreds of millions if results turn out positive. At certain points in the innovation process, the goals of research physicians and industry executives may not align at all.

"The solution is not to waive the concerns and say that everybody is on the same side and wants the same thing. It just ain't so," said Saini. "The solution needs to be a more structured and focused change in how we do things."

Also lacking are arguments that industry funding is critical to support research and that regulation of conflicts of interest slows innovation, according to Dr. Roy Poses, a clinical associate professor of medicine at Brown University in Rhode Island. In an email to CMAJ, Poses said that advocates for more physician-industry "collaboration" appear to have "largely dismissed the evidence and logic underlining concerns about conflicts of interest in health care," noting in particular the many studies that indicate industryfunded research is more likely to produce positive results.

These advocates have also "failed to justify their arguments that we must rely on industry for support of biomedical and clinical research," wrote Poses. "Our current reliance was not inevitable, but created by political decisions that can be challenged. I hope our prestigious medical journals can focus more on dispassionate discussion based on evidence and logic, rather than allowing hope for new innovations to lead to excess hype." — Roger Collier, CMAJ

CMAJ 2016. DOI:10.1503/cmaj.109-5180 